\section{Self-Perceived Oral Health Influences Tooth Brushing in Preschool Children}

Bernardo Antonio Agostini ${ }^{1}$, Rômulo Vaz Machry ${ }^{1}$, Carlos Roberto da Silva Teixeira1, Chaiana Piovesan², Marta Dutra Machado Oliveira', Carmela Rampazzo Bresolin'1, Thiago Machado Ardenghi ${ }^{1}$

\author{
'Departament of Stomatology, \\ School of Dentistry, UFSM - \\ Federal University of Santa \\ Maria, Santa Maria, RS, Brazil \\ ${ }^{2}$ School of Dentistry, UNIFRA \\ - Franciscano University, \\ Santa Maria, RS, Brazil \\ Correspondence: Prof. Dr. \\ Thiago Machado Ardenghi, Rua \\ Floriano Peixoto, 1184, 97500- \\ 124 Santa Maria-RS, Brasil. Tel: \\ +55-55-9998-9694. e-mail: \\ thiardenghi@hotmail.com
}

This study assessed the influence of socioeconomic and clinical factors, as well as parent's perception of child's oral health on the toothbrushing frequency of 0-5-year-old children. The study was carried out in Santa Maria, RS, Brazil, during the National Children's Vaccination Day, and 478 children aged 0 - 5 years were included. Data were collected by clinical examinations and a structured questionnaire, conducted by 15 calibrated examiners and 30 supports. A questionnaire was filled out by the parents with information about several socioeconomic indicators, perception of child's oral health and frequency of tooth brushing. The main outcome was collected by the question: "How many times a day do you brush your child's teeth?". Multivariable Poisson regression model taking into account the cluster sample was performed to assess the association between the predictors and outcome. Children whose parents related worse perception of child's oral health showed less tooth brushing frequency (PR 1.23; 1.06 - 1.43). Young children brush their teeth less than the older ones (PR 0.90; $0.84-0.96)$; and lack of visit to a dentist was predictor for less tooth brushing frequency (PR 1.29; 1.05 - 1.59). Parent's perception of child oral health influence children's healthy behaviors, supporting the evidence that psychosocial factors are strong predictors of children's oral health.
Key Words: self-perception, tooth brushing, preschool children.

\section{Introduction}

Dental caries remains the most prevalent oral disease (1). In Brazil, the latest national population-based oral health survey (2), demonstrated that only $46.9 \%$ of children aged 5 years were caries-free. In the United States, dental caries has been considered the most prevalent chronic disease in the childhood, with more than $40 \%$ of children under 5 years of age with at least one decayed, missing or filled tooth in early childhood (1). Moreover, a previous study suggested that the occurrence of dental caries could be explained by a range of socioeconomic and biological factors (3).

In this context, the accumulation of dental plaque (also described as a biofilm) has been considered a primary cause of dental caries (4). Oral hygiene practices to control biofilm development and toothbrushing have been described as a simple method for plaque removal and effective strategies to control oral diseases. The American Academy of Pediatric Dentistry (AAPD) suggests that oral hygiene should start with the eruption of first primary tooth, and must be performed by the parents at least twice a day (5).

Although the etiological mechanisms of dental caries are well known, child's oral health behaviors are influenced by parents' knowledge and beliefs, which will affect directly oral health care (6). In early childhood, generally, parents are responsible for child's oral health care (7). Parent's perceptions about children's oral health can influence health behaviors such as toothbrush frequency and use of healthcare services $(6,8)$.
Studies assessing the influence of self-perceived oral health on toothbrushing frequency are scarce $(9,10)$. Therefore, this cross-sectional study assessed the influence of socioeconomic factors, clinical conditions and parents' oral health perception on the toothbrush frequency in preschool children.

\section{Methods and Material Sample}

The study was approved by the Ethics Committee of the Federal University of Santa Maria and the School of Dentistry of the University of São Paulo, Brazil

A survey was conducted with a representative sample of 1-5-year-old children of Santa Maria, RS, Brazil. Santa Maria is a medium-sized city located in Southern Brazil; the city has an estimated population of 261,031 inhabitants, including 18,420 children aged $0-5$ years (20). According to the Ministry of Health, the vaccination program has had a consistent uptake rate of over $97 \%$.

To determine a sample size for assessing the association between the child tooth brushing frequency and independent variables, the following parameters were adopted: 5\% standard error, 80\% power, 95\% confidence interval, 10\% non-response, ratio unexposed to exposed 2:1 and a prevalence ratio to be detected of at least 1,8. As a multistage instead of simple random sampling was used, a design effect of 1.4 was applied. The minimum 
sample size to satisfy these requirements was estimated to be 456 children.

\section{Data Collection}

The study was conducted with children who attended the National Day of Children's Vaccination held in June 2010. Participants were randomly chosen among all children visiting the health centers in the municipality of Santa Maria. Health centers were used as sampling points because the city is divided into 5 regions, and each one has public health centers that are responsible for the vaccination of the inhabitants in that area. Multistage sampling considered all health centers with a dental office as primary survey units, and 15 out of 28 health centers were randomly selected. The selected centers accounted for nearly $85 \%$ of the children in the vaccination program. The sample was inversely weighted by the sampling fraction at each center.

Data were collected through clinical oral examinations and structured interviews, conducted by 15 examiners and 30 supports. They were trained and calibrated; interand intra-examiner reliability were assessed and a total of 36 hours were spent on training and calibration. One benchmark examiner conducted the clinical training and calibration sessions.

Children were examined while seated on a dental chair under conventional dental illumination. Visual examinations for ICDAS criteria (11) were conducted with plane dental mirrors and WHO periodontal probes. Wet gauze pads, periodontal probes, toothbrushes and dental floss were used to remove dental plaque present on the surfaces. Socioeconomic and demographic variables such as: age, gender, race, family income, mother's schooling, visits to the dentist, reason for the visit and participation in school activities of the children were assessed by the interview. Age was categorized in 12 to 35 and 36 to 59 months. Family income was measured in terms of Brazilian minimum wage, a standard way for this assessment, which corresponds nearly to US $\$ 300,00$ at the data-gathering period. For mother's schooling, 8 years of formal education was used as a cut-point, which in Brazil corresponds to primary school. Visits to the dentist were considered when the participant attended any dental care service in the previous 6 months and the reason of the visit (preventive or other than preventive); for child school activities, parents were asked if they participated or not of any kind of child activity in the school.

Data about the parents' perceptions of their child's oral health were measured by the question "How do you describe your child's oral health?", with two possible answers 1) Worse or equal than that of other children or 2) Better than that of other children. The feasibility of the questionnaire was previously assessed in a sample of 20 parents during the calibration process. More details about the methods were described previously in an epidemiological survey of preschool children, involving cavitated and noncavitated caries lesions (12).

\section{Statistical Analysis}

Data were analyzed using STATA 12.0 software (Stata Corp., College Station, TX, USA). The outcome was the toothbrush frequency, measured by the following question: "How many times in a day do you brush your child's teeth?" This was dichotomized into ' $\geq 3$ times a day' and 'less than 3 times a day'.

Multivariable Poisson regression model was performed to assess the association between the predictor variables and the outcome. Only the variables that presented a $p$-value $\leq 0.20$ in the unadjusted analysis for entry into the model were considered; they were retained in the final model only if they had a $p$-value $\leq 0.05$ after adjustment. Mother's schooling and mother's participation in child's school activities were retained in the final model as possible confounders. The analyses took into account the sample weight using the "svy" commands in Stata for complex data samples.

\section{Results}

A total of 478 children were examined; 232 (48.54\%) boys and 246 girls (52.46\%). Most of the children were aged between 48-59 months. Predominantly White children were enrolled in the survey (79.29\%). Fathers' and mothers' education reached closely the same values: nearly $56 \%$ studied eight years or more, and nearly half of the mothers were employed. Socioeconomic factors, clinical conditions and parent's perception of child oral health data are summarized in Table 1. The prevalence of dental caries was $33.68 \%(n=161)$, and approximately $90 \%$ of the parents declared they brushed their children's teeth daily.

Table 2 shows the toothbrush frequency and associated variables. Unadjusted analyses showed that the prevalence of children's dental brushing was associated with age, parent's perception of children's oral health, mother's schooling, search for dental services and participation in child's school activities.

After the adjusted regression analysis, children's age, parent's perception of the child's oral health and having visited the dentist remained associated with the prevalence of toothbrush frequency. The oldest children were more likely to brush their teeth than the youngest ones. Furthermore, children whose parent's perception was worse or equal than that of other children had a low toothbrush frequency (PR: 1,23, Cl: 1,06-1,43). Children who did not visit the dentist in the previous year were less likely to brush their teeth (PR:1.28, Cl: 1 03-1.57). 


\section{Discussion}

The association between children's tooth brushing frequency and psychosocial, socioeconomic and clinical factors was assessed. In general, the results demonstrated that parent's self-perception of child's oral health is an important predictor for tooth brushing frequency.

The main results confirm the hypothesis that parents' unfavorable perception of their children's oral health is associated with low tooth brushing frequency. Psychosocial theory could explain the relation between the poor selfperceived oral health and low toothbrush frequency. Self-perception on oral health is a psychosocial factor that influences directly health behavioral choices; people who experience psychosocial stress are more likely to make unhealthy choices (13). Moreover, perception on oral health is closely related with social disparities $(14,15)$. Inequalities in oral health have been associated with a range of health outcomes; generally individuals in the lower socioeconomic groups tend to rate their oral health as poor and present worse health outcomes. Such inequities could affect both the child and family wellbeing, resulting in a negative impact on daily performance and the quality of life by the underlying influence of psychosocial, environmental and material deprivation $(16,17)$. Therefore, parents' perception of their child's oral health is closely related with the development of early healthy behaviors, reflecting in a good health status for entire life.

Regarding the differences in toothbrushing frequency according to the age, the obtained data corroborate those of a previous study that assessed the relation between maternal psychosocial variables and children's tooth brushing habits in low income African-American families (6). Their findings showed that 1-3 years-old children brushed the teeth less than the older children. This increase of tooth brushing for older children agrees with previous reports (18). On the other hand, it was shown that age was not associated with toothbrushing frequency: children younger than 1 year and over 2 years of age presented similar prevalence (10). Nevertheless, it is know that over the years children are more likely to develop new skills. Children under 5 years of age present a rapid mental development (6). Therefore, it is important to encourage the adoption of healthy behaviors at this stage of their life.

In the present study, children who never visited a dentist were more likely to brush their teeth less often. This could be explained by a lack of preventive public programs about tooth brushing (19). It also highlights the importance of an early preventive dental visit as a strategy to establish primary prevention (20). Therefore, strategies to promote access to oral healthcare may have an important contribution in the adoption of healthy habits and early intervention against harmful effects of dental diseases.
This could be important in reducing costs of dental service use, since the resources will be applied in the main factors of disease, and preventive for future oral diseases (21).

The results of this study must be considered with caution. Children in the evaluated age group are unable to fill out the questionnaire by themselves, and thus parents' perception of child's oral health was used as a proxy $(8,15)$. Piovesan et al. (15) demonstrated that the use of proxy judgments concerning children's oral health can be considered a feasible option to assess the children's perception of oral health related quality of life. Toothbrush

Table 1. Sociodemographic and clinical characteristics of the sample

\begin{tabular}{|c|c|c|}
\hline Variable & $\mathrm{N}$ & $\%$ \\
\hline \multicolumn{3}{|l|}{ Gender } \\
\hline Male & 232 & 48.54 \\
\hline Female & 246 & 51.46 \\
\hline \multicolumn{3}{|l|}{ Age (months) } \\
\hline $12-35$ & 186 & 38.91 \\
\hline $36-59$ & 292 & 61.09 \\
\hline \multicolumn{3}{|l|}{ Skin color } \\
\hline White & 379 & 79.29 \\
\hline Non-White & 99 & 20.71 \\
\hline \multicolumn{3}{|l|}{ Monthly income } \\
\hline$\geq 2 \mathrm{BMW}^{*}$ & 174 & 38.58 \\
\hline$<2 \mathrm{BMW}^{*}$ & 277 & 61.42 \\
\hline \multicolumn{3}{|l|}{ Mother's education } \\
\hline$\geq 8$ years & 268 & 56.78 \\
\hline$<8$ years & 204 & 43.22 \\
\hline \multicolumn{3}{|l|}{ Mother's perception of child's oral health } \\
\hline Better than that of other children & 205 & 43.52 \\
\hline Worse or equal than that of other children & 266 & 56.48 \\
\hline \multicolumn{3}{|l|}{ Visit a dentist } \\
\hline Yes & 112 & 23.68 \\
\hline No & 361 & 76.32 \\
\hline \multicolumn{3}{|l|}{ Reason for the dental visit } \\
\hline Preventive & 82 & 67.77 \\
\hline Other than preventive & 39 & 32.23 \\
\hline \multicolumn{3}{|l|}{ Overjet } \\
\hline$\leq 3 \mathrm{~mm}$ & 308 & 86.52 \\
\hline$>3 \mathrm{~mm}$ & 48 & 13.48 \\
\hline \multicolumn{3}{|l|}{ Anterior open bite } \\
\hline No & 336 & 73.20 \\
\hline Yes & 123 & 26.80 \\
\hline \multicolumn{3}{|l|}{ Child school activity } \\
\hline Participate & 187 & 39.70 \\
\hline Do not Participate & 284 & 60.30 \\
\hline
\end{tabular}

*BMW: Brazilian minimum wage (approximately US\$300 during the data gathering). 
frequency isolated is not the best predictor for children's oral hygiene due to the low validity of oral hygiene questions. Cascaes et al. (22) suggest that reports from mothers for assessing their children oral hygiene cannot substitute clinical examination. However, toothbrush frequency is still a positive oral health promoting behavior even when measured by a questionnaire. Notwithstanding, such methodological option was frequently used to assess toothbrush frequency in previous studies $(5,6,10,14)$. The present data could be overestimated due to social desirability response bias, a bias that refers to the tendency to give responses in a socially desirable direction instead of reporting the true event or perception, a limitation that relies on self-report (10).

Although this study followed a cross-sectional design, which prevents hypothesis of causality, it is believed that the results could bring important contributions that may contribute to public management of policies for oral health care in this age-group. It was tried to use a representative sample of preschool children obtained by a random selection process at different sample centers around the city. This process avoided a bias, which might occur if the sample were collected in a clinical setting. Nevertheless, such a process provides sound conclusions about the research

Table 2. Daily toothbrushing frequency and associated factors. Unadjusted and adjusted Poisson Regression Analysis

\begin{tabular}{|c|c|c|c|c|}
\hline Variable & $\geq 3$ times & $<3$ times & PRcrude $(95 \% \mathrm{Cl})$ & PRadj (95\% Cl) \\
\hline & & & \multicolumn{2}{|c|}{$<3$ times } \\
\hline Gender & & & $p=0.32$ & \\
\hline Male & $75(35.21)$ & $138(64.79)$ & 1 & \\
\hline Female & $92(39.83)$ & $139(60.17)$ & $0.93(0.80-1.07)$ & \\
\hline Age (months) & & & $p=0.00$ & $p=0.00$ \\
\hline $12-35$ & $42(25.15)$ & $117(42.24)$ & 1 & 1 \\
\hline $36-59$ & $125(74.85)$ & $160(57.76)$ & $0.76(0.66-0.88)$ & $0.83(0.71-0.95)$ \\
\hline Skin color & & & $p=0.90$ & \\
\hline White & $133(37.46)$ & $222(62.54)$ & 1 & \\
\hline Black & $34(38.20)$ & $55(61.80)$ & $0.99(0.82-1.18)$ & \\
\hline Income & & & $p=0.94$ & \\
\hline$\geq 2 \mathrm{BMW}$ & 63 (37.28) & $106(62.72)$ & 1 & \\
\hline$<2 \mathrm{BMW}$ & 93 (36.90) & $159(63.10)$ & $1.00(0.86-1.17)$ & \\
\hline Mother's education & & & $p=0.15$ & $p=0.12$ \\
\hline$\geq 8$ years & $104(40.94)$ & $150(59.06)$ & 1 & 1 \\
\hline$<$ 8years & $63(34.24)$ & $121(65.76)$ & $1.11(0.96-1.29)$ & $1.13(0.98-1.30)$ \\
\hline Mother's perception of child's oral health & & & $p=0.01$ & $p=0.00$ \\
\hline Better than other children & $87(45.08)$ & $106(54.92)$ & 1 & 1 \\
\hline Worse or equal than other children & $70(31.67)$ & $151(68.33)$ & $1.24(1.06-1.45)$ & $1.23(1.06-1.43)$ \\
\hline Visit a dentist & & & $p=0.00$ & $p=0.02$ \\
\hline Yes & $56(50.91)$ & $54(49.09)$ & 1 & 1 \\
\hline No & $108(32.73)$ & $222(67.27)$ & $1.37(1.12-1.68)$ & $1.29(1.05-1.59)$ \\
\hline Reason for dental visit & & & $p=0.64$ & \\
\hline Preventive & $42(51.85)$ & $39(48.15)$ & 1 & \\
\hline Other than preventive & $18(47.37)$ & $20(52.63)$ & $1.09(0.75-1.60)$ & \\
\hline Overjet & & & $p=0.44$ & \\
\hline$\leq 3 \mathrm{~mm}$ & 105 (36.71) & 181 (63.29) & 1 & \\
\hline$>3 \mathrm{~mm}$ & $14(31.11)$ & $31(68.89)$ & $1.09(0.88-1.35)$ & \\
\hline Anterior open bite & & & $p=0.38$ & \\
\hline No & $114(36.31)$ & $200(63.69)$ & 1 & \\
\hline Yes & $48(41.03)$ & $69(58.97)$ & $0.92(0.78-1.10)$ & \\
\hline Child school activity & & & $p=0.01$ & $p=0.21$ \\
\hline Participate & 79 (44.38) & $99(55.62)$ & 1 & 1 \\
\hline Do not participate & $84(32.18)$ & $177(67.82)$ & $1.22(1.04-1.42)$ & $1.11(0.96-1.30)$ \\
\hline
\end{tabular}

*PR $(95 \% \mathrm{Cl})$ : prevalence rate. 
question for all preschoolers living in Santa Maria.

The findings of the present study suggest that toothbrushing frequency is influenced by parents' perceptions of their child's oral health. This could have important implication in planning appropriate programs for oral health aimed to reduce inequalities in the burden of disease across populations groups. Measurements of selfperceived oral health walk hand in hand with oral survey as a key outcome in health care and patient needs (23). Therefore, the planning of preventive strategies should take into account psychosocial factors that influence healthy habits in the early childhood. This is especially important in promoting tooth brushing, which is closely related with healthy behaviors. Investment in such programs should include components that determine the perceived needs of the individuals, rather than being focused only on dental disease. This is properly described when considering the limitations of biomedical approaches focused mainly on biological predictors to reduce health inequalities and promote oral health (24).

\section{Resumo}

0 estudo avaliou a influência de fatores socioeconômicos, clínicos e a percepção dos pais quanto à saúde de seus filhos na frequência de escovação de pré-escolares de 0 a 5 anos de Santa Maria-RS, Brasil. 0 estudo foi realizado em Santa Maria, Brasil, durante o Dia Nacional de Vacinação das Crianças e 478 crianças de 0 - 5 anos foram incluidas. Os dados foram coletados por meio de exames clínicos e por um questionário estruturado, realizados por 15 examinadores calibrados e 30 auxiliares. Os responsáveis forneceram informações sobre diversos indicadores socioeconômicos, auto-percepção de saúde bucal e frequência de escovação dentária. 0 principal desfecho foi coletado pela pergunta "Quantas vezes por dia você escova os dentes de seu filho?". Os dados foram analisados utilizando modelo de regressão de Poisson, considerando pesos relativos à amostragem complexa. Pais que relataram pior percepção de saúde bucal dos seus filhos em relação às outras crianças apresentavam uma menor frequência de escovação (RP 0,23; IC: 1,06 - 1,43). Crianças mais novas escovavam menos os dentes que as de idade mais elevada (RP 0,$90 ;$ IC: $0,84-0,96$ ) e a não-procura pelo dentista foi preditor para menor frequência de escovação (RP 1,29; IC: 1,05 - 1,59). A percepção dos pais influencia hábitos saudáveis da criança, suportando a evidência de que aspectos psicossociais são fortes preditores de saúde bucal na infância.

\section{References}

1. US Department of Health and Human Services U. Oral health in America : a report of the Surgeon General. Rockville; 2000 p. 158-168.

2. Ardenghi TM, Piovesan C, Antunes JL. Inequalities in untreated dental caries prevalence in preschool children in Brazil. Rev Saúde Pública 2013;47:129-137.

3. Piovesan C, Mendes FM, Ferreira F V, Guedes RS, Ardenghi TM. Socioeconomic inequalities in the distribution of dental caries in Brazilian preschool children. J Public Health Dent 2010;70:319-326.

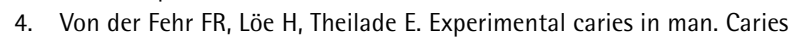
Res 1970;4:131-148.

5. Khadri FA, Gopinath VK, Hector MP, Davenport ES. How pre-school children learn to brush their teeth in Sharjah, United Arab Emirates. Int J Paediatr Dent 2010;20:230-234.

6. Finlayson TI, Siefert K, Ismail AI, Sohn W. Maternal self-efficacy and 1 5 -year-old children's brushing habits. Community Dent Oral Epidemiol 2007;35:272-281.

7. Watt RG. From victim blaming to upstream action: tackling the social determinants of oral health inequalities. Community Dent Oral Epidemiol 2007;351-311.

8. Jokovic A, Locker D, Guyatt G. How well do parents know their children? Implications for proxy reporting of child health-related quality of life. Qual Life Res 2004;13:1297-1307.

9. Perera I, Ekanayake L. Influence of oral health-related behaviours on income inequalities in oral health among adolescents. Community Dent Oral Epidemiol 2011;39:345-351.

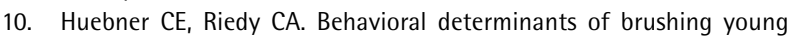
children's teeth: implications for anticipatory guidance. Pediatr Dent 2010;32:48-55.

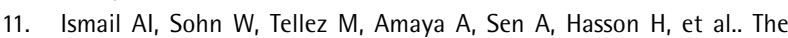
International Caries Detection and Assessment System (ICDAS): an integrated system for measuring dental caries. Community Dent Oral Epidemiol 2007;35:170-178.

12. Piovesan C, Ardenghi TM, Guedes RS, Ekstrand KR, Braga MM, Mendes FM. Activity assessment has little impact on caries parameters reduction in epidemiological surveys with preschool children. Community Dent Oral Epidemiol 2013;41:204-211.

13. Elstad JI. The psycho-social perspective on social inequalities in health. Sociol Health IIIn 1998;20:598-618.

14. Levin $\mathrm{K}$ A, Currie $\mathrm{C}$. Inequalities in toothbrushing among adolescents in Scotland 1998 - 2006. Health Educ Res 2009;24:87-97.

15. Piovesan C, Guedes RS, Ardenghi TM, Antunes JLF. Influence of selfperceived oral health and socioeconomic predictors on the utilization of dental care services by schoolchildren. Braz Oral Res 2011;25:143149.

16. Wandera M, Kayondo J, Engebretsen IMS, Okullo I, Astrøm AN. Factors associated with caregivers' perception of children's health and oral health status: a study of 6- to 36-month-olds in Uganda. Int J Paediatr Dent 2009;19:251-262.

17. Sabbah W, Tsakos G, Sheiham A, Watt RG. The role of health-related behaviors in the socioeconomic disparities in oral health. Soc Sci Med 2009;68:298-303.

18. Maes L, Vereecken C, Vanobbergen J, Honkala S. Tooth brushing and social characteristics of families in 32 countries. Int Dent J 2006;56:159-167.

19. Kramer PF, Ardenghi TM, Ferreira $S$, Fischer $L$ de $A$, Cardoso $L$, Feldens CA. Use of dental services by preschool children in Canela, Rio Grande do Sul State, Brazil. Cad Saúde Pública 2008;24:150-156.

20. Ardenghi TM, Vargas-Ferreira F, Piovesan C, Mendes FM. Age of first dental visit and predictors for oral healthcare utilisation in preschool children. Oral Heal Prev Dent. 2012;10:17-28.

21. Savage MF, Lee JY, Kotch JB, Vann WF. Early preventive dental visits: effects on subsequent utilization and costs. Pediatrics 2004; 114:e418-e423

22. Cascaes AM, Peres KG, Peres MA, Demarco FF, Santos I, Matijasevich A, et al.. Validity of 5-year-old children's oral hygiene pattern referred by. Rev Saude Publica. 2011;45:1-7.

23. McGrath C, Broder HL, Wilson-Genderson M. Assessing the impact of oral health on the life quality of children : implications for research and practice. Community Dent Oral Epidemiol 2004;32:81-85.

24. Thomson WM, Sheiham A, Spencer J. Sociobehavioral aspects of periodontal disease. Periodontol 2000 2012;60:54-63.

Received February 28, 2014 Accepted June 3, 2014 